\title{
A morphological study of human cadaveric liver and its clinical importance in Gujarat
}

\author{
Pankaj Maheria ${ }^{1}$, Sanjay Vikani ${ }^{2, *}$ \\ ${ }^{1,2}$ Associate Professor, Dept. of Anatomy, ${ }^{1}$ GMERS Medical College, Dharpur, Patan, Gujarat, ${ }^{2}$ Banas Medical College and Research \\ Institute, Palanpur, Gujarat, India
}

*Corresponding Author: Sanjay Vikani

Email: doc.vikani@gmail.com

\begin{abstract}
The liver is the largest gland of the body. It is involved in various metabolic activities. It is present in right hypochondrium, epigastric and reach up to left hypochondrium. Due to presence of falciform ligamentum, liver is divided into anatomical 5/6 right and 1/6 left lobe. During intrauterine life right lobe is larger due to haematopoiesis, but the haemopoietic function of liver is diminishes sufficiently in last two month leads to progressive reduction of its size which mostly affect left lobe. The study was carried out on 50 embalmed liver present in department of anatomy, GMERS medical college, Dharpur, Patan, Gujarat over the period of three year. Liver observed macroscopically for presence of any accessory lobe or fissure, then take photograph for record and further analysis. In our study out of 50 specimens $29(58 \%)$ specimen normal without any morphological changes, while in $21(42 \%)$ there are various changes. Out of $42 \%$ there is presence of accessory lobe in 7(14\%), accessory fissure \& grooves in 9(18\%), Abnormal elongation of left lobe in 4 (8\%) specimen and Riedel's lobe in $1(2 \%)$ specimen. To identify primary or metastatic hepatic carcinoma hepatic imaging technique is best tool, in which various major fissure \& lobes are very important landmark to mark the lobar anatomy and liver lesions. So it is helpful to radiologist as well as the surgeons to plan surgery accordingly.
\end{abstract}

Keywords: Liver, Accessory lobe, Accessory fissure, Caudate lobe, Quadrate lobe.

\section{Introduction}

The liver is the largest gland of the body. It is involved in various metabolic activities due to various products by its exocrine part which secret bile and endocrine part liberates some useful chemical substance like glucose, plasma protein, heparin etc. it is present in right hypochondrium, epigastric and reach up to left hypochondrium. ${ }^{1}$ There is presence of ' $\mathrm{H}$ ' shaped fissure on postero-inferior surface of liver which include groove for inferior vena cava, fossa for gall bladder, fissure for ligamentum venosum and ligamentum teres, because of presence of falciform ligamentum liver is divided into anatomical 5/6 right and 1/6 left lobe. On the basis of intrahepatic distribution of hepatic artery, portal vein and biliary duct, the liver can be divided into the right and left functional lobes; they do not correspond with anatomical lobes of liver. The physiological lobes are separated by plane passing on antero superior surface along a line joining cystic notch to groove for inferior vena cava. The right lobe is subdivided into anterior and posterior segments and left lobe into medial and lateral segments. Thus there are four segments which have surgical importance. There is various another lobes like caudate lobe on posterior surface which represent physiological left lobe of liver, Quadrate lobe on inferior surface which represent physiological left lobe, tongue like projection from inferior border of liver as Riedel's lobe. ${ }^{1,2}$

Current understanding of the functional anatomy of the liver is based on Couinaud's division of the liver into eight (subsequently nine) functional segment based distribution of portal vein. ${ }^{3}$ Liver is larger in children due to haemopoietic function in foetal life and occupies the 2/5 of the abdomen. It develops from an endodermal evagination of foregut and from septum transversum. The growth of liver in early part of development is profuse; affecting both the lobes almost equally, as right lobe is soon become larger due to haematopoiesis, but the haemopoietic function of liver is diminishes sufficiently in last two month leads to progressive reduction of its size which mostly affect left lobe. Minor variations of liver lobulation are common, but major congenital variations of liver are rare. ${ }^{4,5}$ To identify primary or metastatic hepatic carcinoma hepatic imaging technique is best tool, in which various major fissure \& lobes are very important landmark to mark the lobar anatomy and liver lesions. In today's world there is maximum use of minimum invasive technique and advance imaging tools, it is very much important to know the exact anatomy and commonly occurring variations in liver. ${ }^{6}$

\section{Materials and Methods}

The study was carried out on 50 liver specimens present in Department of Anatomy, GMERS Medical College, Dharpur, Patan, Gujarat over the period of three year. These specimens were removed carefully during routine dissection of abdomen. Afterwards the specimens were cleaned and observed macroscopically for change in size and shape, presence of any accessory lobe or fissure. Photographs were taken for record and further analysis. Any pathological or damaged specimens were excluded from the study.

\section{Results and Discussion}

In the present study, out of 50 specimens examined, we found $29(58 \%)$ specimen normal without any morphological changes, while in $21(42 \%)$ specimen we found various morphological changes. Out of $21(42 \%)$ specimen, there is presence of accessory lobe in $7(14 \%)$ specimen, development of accessory fissure \& grooves in $9(18 \%)$ specimen, abnormal elongation of left lobe in $4(8 \%)$ specimen and Riedel's lobe (which is abnormal projection from right lobe beyond costal margin) in 1(2\%) specimen. 


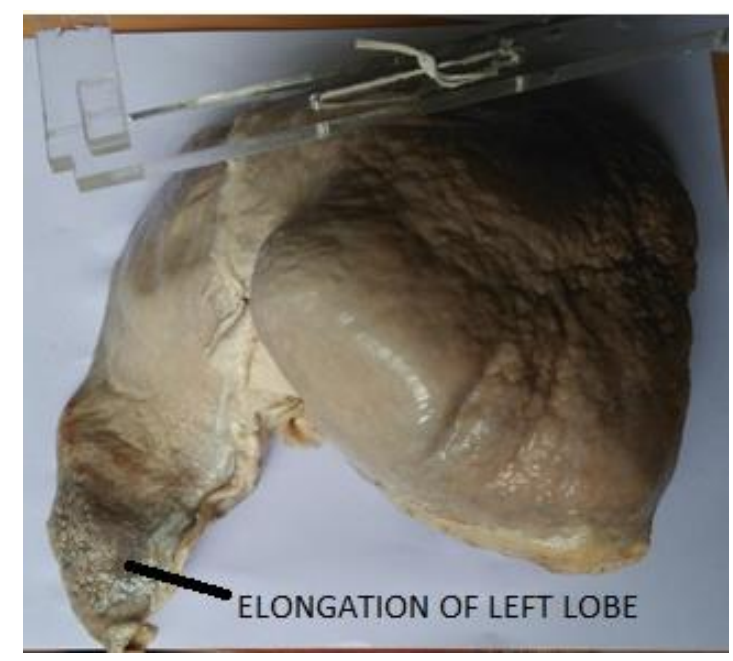

Fig. 1: Elongation of left lobe

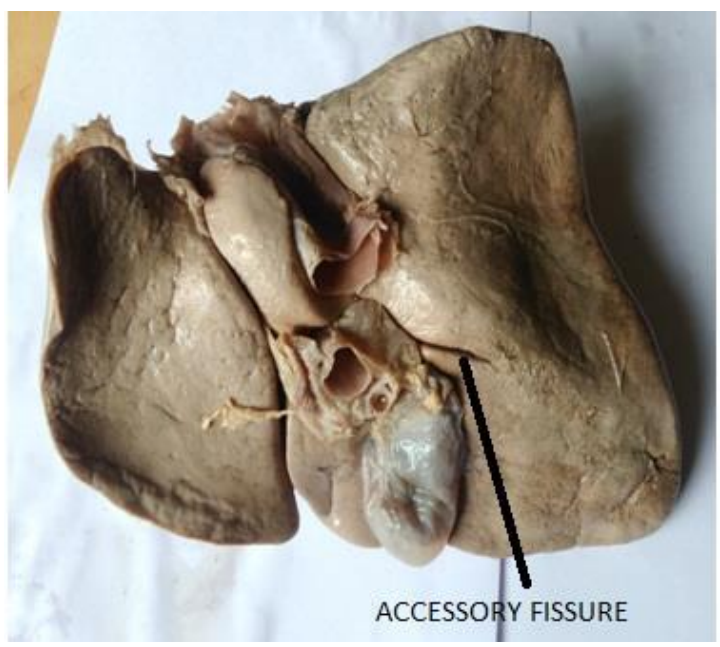

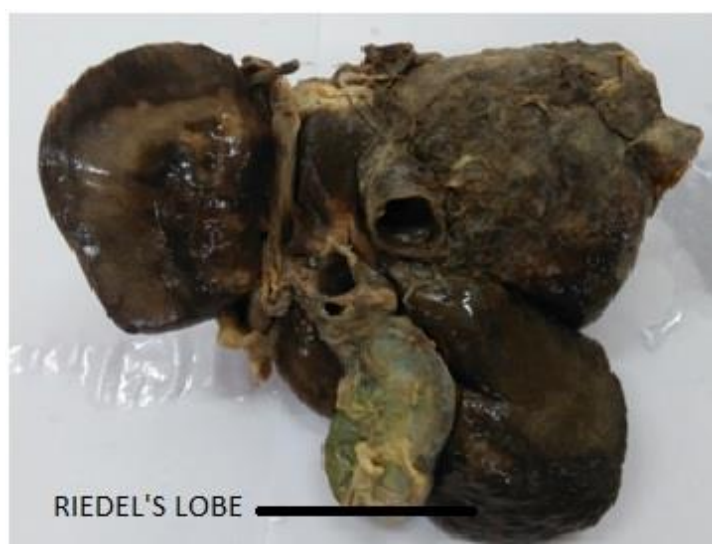

Fig. 3: Riedel's lobe

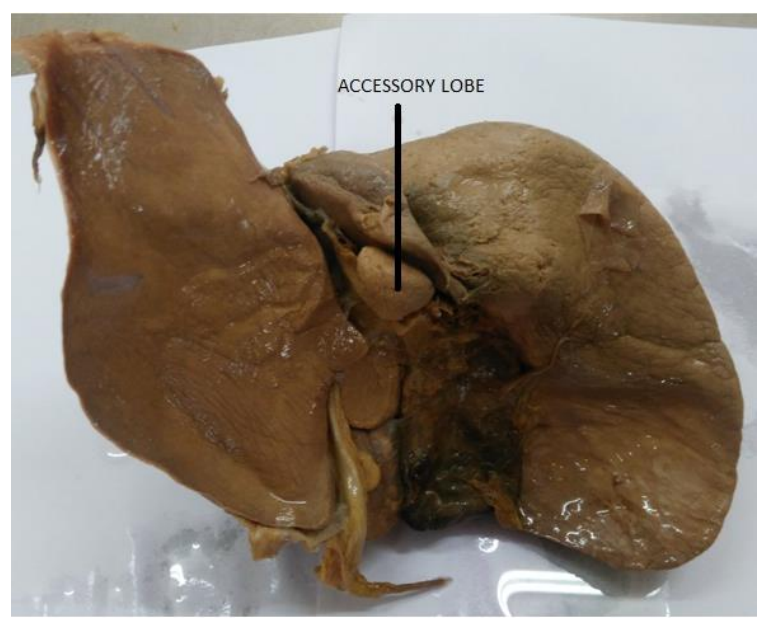

Fig. 4: Accessory lobe

Fig. 2: Accessory fissure

Table 1: Morphological variations of liver

\begin{tabular}{|l|c|c|c|}
\hline S. No. & Type of variation & No. of specimen & Percentage (\%) \\
\hline 1. & Elongation of left lobe (Fig. 1) & 4 & $8 \%$ \\
\hline 2. & Accessory fissures (Fig. 2) & 9 & $18 \%$ \\
\hline 3. & Riedel's lobe (Fig. 3) & 1 & $2 \%$ \\
\hline 4. & Accessory lobes (Fig. 4) & 7 & $14 \%$ \\
\hline
\end{tabular}

Observations of the present study were compared with the findings of the other researchers.

Table 2: Observations Compare with different study

\begin{tabular}{|l|c|c|c|c|c|c|c|}
\hline S. No. & Author & $\begin{array}{c}\text { No. of liver } \\
\text { specimen }\end{array}$ & $\begin{array}{c}\text { Elongation of } \\
\text { left lobe (\%) }\end{array}$ & $\begin{array}{c}\text { Accessory } \\
\text { fissure (\%) }\end{array}$ & $\begin{array}{c}\text { Riedel's } \\
\text { lobe (\%) }\end{array}$ & $\begin{array}{c}\text { Accessory } \\
\text { Lobe (\%) }\end{array}$ & $\begin{array}{c}\text { Total } \\
\text { variation (\%) }\end{array}$ \\
\hline 1 & Present study & 50 & 8 & 18 & 2 & 14 & 42 \\
\hline 2 & Hussein Muktyaz et al $^{7}$ & 41 & - & 12.1 & - & 14.6 & 26.7 \\
\hline 3 & Joshi et al $^{8}$ & 50 & 32 & 30 & - & 18 & 39 \\
\hline 4 & Dr.Abhilasha Wahane $^{9}$ & 50 & - & 20 & 4 & 16 & 56 \\
\hline 5 & Deepa G $^{10}$ & 40 & 5 & - & 2.5 & - & 15 \\
\hline 6 & Dr.S.Saritha $^{11}$ & 50 & 4 & 30 & 6 & 16 & 34 \\
\hline
\end{tabular}

As shown in Table 2, Joshi et al, Dr. Abhilasha Wahane and Dr. S. Saritha conducted study on same no. of specimen as present study. They found nearby variation of accessory lobe like $18 \%, 16 \% \& 16 \%$ respectively, compare to present study $16 \%$. For accessory fissure, Joshi et al and Dr. S. Saritha found $30 \%$ which is higher than present study of 
$18 \%$. Elongation of left lobe variation found $32 \%$ by Joshi et al, which is much higher as compared to present observation of $8 \%$. Ridel's lobe variation is almost equal in every study. So overall variation in present study is $42 \%$ which is almost same with Joshi et al \& Dr. S. Saritha with $39 \%$ \& 34\% respectively, while present data contradicted with study of Hussein Muktyaz et al \& Deepa G, where overall variation is $26.7 \%$ \& $15 \%$.

\section{Conclusion}

The present study focuses on morphological variations of liver in which there is presence of accessory lobe or fissure. This knowledge is very much important for radiologist to give exact demarcation of various accessory lobes or fissure in final report, and on the basis of which, surgeons will plan the surgery accordingly.

\section{References}

1. A K Datta. Essentials of human Anatomy- part 1, 8th Edition, Current book international, 2008:237-243.

2. B D Chaurasia. Human Anatomy- vol: 2, 6th Edition, CBS Publishers, 2013, 308.

3. Standring S. Gray's anatomy 40th Edition. Anatomical Basis of Clinical Practice, Churchill Livingstone, London 2008, p1165.

4. Keith L, Persaud TVN. The developing human, clinically oriented embryology. 8th ed., Elsevier; 2008, 218-220.

5. Datta AK. Essentials of Human Embryology. 9th Ed. Calcutta: Current Books International; 2014, 131-132.
6. Sahani, D. V. \& Kalva, S. P. Imaging the liver. Oncologist, 2004;9(4):385-397.

7. Hussein Muktyaz, Usman Nema, Gupta Rakesh. Morphological variations of liver lobes and its clinical significance in north Indian population. Glob J Med Med Sci 2013;1(1):1-5.

8. Joshi SD, Joshi SS, Athavale SA. Some interesting observations on the surface features of the liver and their clinical implications. Singapore Med J 2009;50:715-719.

9. Abhilasha Wahane, Charulata Satpute. Normal Morphological Variations of Liver Lobes: A Study on Adult Human

Cadaveric Liver in Vidarbha Region. IJSR 2015;4(5):814-816.

10. Deepa G, Shivakumar G L, Morphological study of variations in the lobar pattern of liver. NJIRM 2013;4(4):42-45.

11. S. Saritha, Ramani, Nagajyothi and Yesender. Cadaveric Study of Morphological Variations in the human liver and its Clinical importance. Int J Med Sci Clin Inventions, 2015;2(6):10201031.

How to cite this article: Maheria P, Vikani S. A morphological study of human cadaveric liver and its clinical importance in Gujarat. Indian J Anat Surg Head Neck Brain 2018;4(4):111-113. 